Digital Platforms' Information Concentration:

From Keystone Players to Gatekeepers

Allier savoir et décision

FRÉDÉRIC MARTY

THIERRY WARIN 


\section{$\checkmark$ CIRANO Knowledge into action}

Center for Interuniversity Research and Analysis on Organizations

The purpose of the Working Papers is to disseminate the results of research conducted by CIRANO research members in order to solicit exchanges and comments. These reports are written in the style of scientific publications. The ideas and opinions expressed in these documents are solely those of the authors.

Les cahiers de la série scientifique visent à rendre accessibles les résultats des recherches effectuées par des chercheurs membres du CIRANO afin de susciter échanges et commentaires. Ces cahiers sont rédigés dans le style des publications scientifiques et n'engagent que leurs auteurs.

CIRANO is a private non-profit organization incorporated under the Quebec Companies Act. Its infrastructure and research activities are funded through fees paid by member organizations, an infrastructure grant from the government of Quebec, and grants and research mandates obtained by its research teams.

Le CIRANO est un organisme sans but lucratif constitué en vertu de la Loi des compagnies du Québec. Le financement de son infrastructure et de ses activités de recherche provient des cotisations de ses organisations-membres, d'une subvention d'infrastructure du gouvernement du Québec, de même que des subventions et mandats obtenus par ses équipes de recherche.

\section{CIRANO Partners - Les partenaires du CIRANO}

Corporate Partners - Partenaires corporatifs

Autorité des marchés financiers

Bank of Canada

Bell Canada

BMO Financial Group

Business Development Bank of Canada

Caisse de dépôt et placement du Québec

Desjardins Group

Énergir

Hydro-Québec

Innovation, Science and Economic Development Canada

Intact Financial Corporation

Manulife Canada

Ministère de l'Économie, de la Science et de l'Innovation

Ministère des finances du Québec

National Bank of Canada

Power Corporation of Canada

PSP Investments

Rio Tinto

Ville de Montréal

Academic Partners - Partenaires universitaires

Concordia University

École de technologie supérieure

École nationale d'administration publique

HEC Montréal

McGill University

National Institute for Scientific Research

Polytechnique Montréal

Université de Montréal

Université de Sherbrooke

Université du Québec

Université du Québec à Montréal

Université Laval

CIRANO collaborates with many centers and university research chairs; list available on its website. Le CIRANO collabore avec de nombreux centres et chaires de recherche universitaires dont on peut consulter la liste sur son site web.

(C) December 2020. Frédéric Marty, Thierry Warin. All rights reserved. Tous droits réservés. Short sections may be quoted without explicit permission, if full credit, including (C) notice, is given to the source. Reproduction partielle permise avec citation du document source, incluant la notice $\mathbb{C}$.

The observations and viewpoints expressed in this publication are the sole responsibility of the authors; they do not necessarily represent the positions of CIRANO or its partners. Les idées et les opinions émises dans cette publication sont sous l'unique responsabilité des auteurs et ne représentent pas nécessairement les positions du CIRANO ou de ses partenaires. 


\title{
Digital Platforms' Information Concentration: From Keystone Players to Gatekeepers
}

\author{
Frédéric Marty *, Thierry Warin ${ }^{\dagger}$
}

\begin{abstract}
Résumé
This article demonstrates the inner relationship between gatekeepers and their complementors and the impact of information sharing on the overall market competition intensity and the economic surplus allocation. Several competition law-based cases are grounded on the incompleteness and information asymmetry in which complementors have to make their decisions. In this article, the situation of the complementors is all the more unfavourable when their partnership with the gatekeeper is a durable one. We use a game theory-based model to explain this trajectory. The informational imperfections undermine the bargaining power of the complementors and raise the potential cost of the exit option out of the ecosystem. In this perspective, we envisage regulatory remedies as data portability as proposed by the E.U. Commission Digital Markets Act.
\end{abstract}

Keywords/Mots-clés: Gatekeeper, Keystone Player, Market Dominance, Innovation, Kill Zones

JEL Codes/Codes JEL: L12, L41, L86

${ }^{*}$ CNRS - GREDEG - Université Côte d'Azur. CIRANO, Montréal.

${ }^{\dagger}$ HEC Montréal. CIRANO, Montréal. OBVIA. 


\section{Introduction}

The vacuum effect is that keystone players may concentrate their complementors' information on their platform, creating a lock-in situation. First, it benefits the complementors, but it may also increase the inelasticity of the complementors' demand. As a result of this vacuum effect, a keystone player can become a monopolistic multi-sided platform on its market.

In this context, on December 15, 2020, the European Commission (E.C.) has produced an important document, titled "Proposal for a Regulation of the European Parliament and the Council on contestable and fair markets in the digital sector (Digital Markets Act)" (DMA). ${ }^{1}$

The context of the DMA is the following:

Digital services have brought important innovative benefits for users and contributed to the internal market by opening new business opportunities and facilitating cross-border trading. Today, these digital services cover a wide range of daily activities including online intermediation services, such as online marketplaces, online social networking services, online search engines, operating systems or software application stores. They increase consumer choice, improve efficiency and competitiveness of the industry and can enhance civil participation in society. However, whereas over 10000 online platforms operate in Europe's digital economy, most of which are SMEs, a small number of large online platforms capture the biggest share of the overall value generated.

Large platforms have emerged benefitting from characteristics of the sector such as strong network effects, often embedded in their own platform ecosystems, and these platforms represent key structuring elements of today's digital economy, intermediating the majority of transactions between end users and business users. Many of these undertakings are also comprehensively tracking and profiling end users. A few large platforms increasingly act as gateways or gatekeepers between business users and end users and enjoy an entrenched and durable position, often as a result of the creation of conglomerate ecosystems around their core platform services, which reinforces existing entry barriers.

As such, these gatekeepers have a major impact on, have substantial control over the access to, and are entrenched in digital markets, leading to significant dependencies of many business users on these gatekeepers, which leads, in certain cases, to unfair behaviour visà-vis these business users.

Our main contribution is to bridge the gap between the inner dynamics of a multi-sided platform (keystone or gatekeeper) and its place on the market. We connect the platform's dynamics complementor contractual and technological relationship with the market share of the platform in the industry. This has interesting lessons for the dynamics of single-homing versus multi-homing possibilities, which we believe is relevant for a healthy market, notably in terms of the pace of innovation (Marty et al., 2020c). In terms of methodology, this is possible thanks to a multidisciplinary approach combining the literature on keystone players from Management Science and the literature on Competition Law and Economics and Industrial Organization.

\footnotetext{
${ }^{1}$ https://eur-lex.europa.eu/legal-content/en/TXT/?qid=1608116887159\&uri=COM\%3A2020\%3A842\%3AFIN
} 
The model highlights the vacuum effect generated by a platform that integrates its complementors' information. The model makes it clear that this "vacuum effect" (the inner dynamics of the multisided platform) has replications on the overall market (the competition law domain). It is particularly interesting since the literature is usually about the collusive aspect of algorithms (Marty, 2017), while here, we remain in the monopolistic dimension of algorithms and the necessity for public policies to evolve (de Marcellis-Warin et al., 2020a).

This article wants to model the platform dynamics - inside and outside - and better understand the implicit assumptions that we find in new proposed regulations such as the DMA. The diagnosis established by the European Commission may raise two types of questions.

The first question relates to the development of barriers to entry in markets characterized by high technological turbulence levels and high innovation rates. The conciliation between a hypothesis of locking in dominant positions and maintaining a high rate of innovation constitutes the first line of thought (see notably Petit, 2020, on this point). In previous research, we developed the hypothesis that the need to strengthen algorithms' performance presupposes a sustained rate of innovation for data collection purposes (Marty and Warin, 2020a, 2020b, 2020d). Another hypothesis is that other digital ecosystems' potential threat always implies the need to sustain investment in innovation to face potential competitive threats (Marty and Warin, 2020c).

The second issue consists of the development of abusive practices within ecosystems. These would have several possible origins. The first is due to phenomena of economic dependence and, often, more specifically, technical dependence. A technological lock-in effect can result from integration into an ecosystem. An equally "effective" effect comes from contractual rules (Bougette and al., 2019). A second possible origin of the development of abusive practices, on which this article focuses, concerns the imperfect information situation in which the complementors evolve vis-à-vis the keystone. We hypothesize that this configuration of incomplete and asymmetrical information is the origin of disloyal behaviours (exploitative and/or exclusionary) towards complementors and that moreover, the informational imperfection increases with the closeness and duration of the partnership. ${ }^{2}$

In other words, digital markets are characterized less by their transparency than by their opacity (natural or constructed ${ }^{3}$ ). However, insertion into an ecosystem can reduce firms' ability to collect information and make informed and autonomous market decisions.

Modern I.O. is based on information imperfections (incompleteness and asymmetrical access). In principle, digitalization could be a way to make markets more transparent by reducing search costs and by making price monitoring constant (web scraping) (Warin and Leiter, 2012; Warin and Troadec, 2016). Paradoxically, the lack of transparency is one of the main concerns of antitrust enforcers.

This article proposes a slightly different domain, not only limited to digital markets narrowly defined but also related to any algorithm-based markets either online and in the brick-and-mortar economy. Indeed, what is truly at stake is machine-learning techniques in decision-driven data-based firms' strategies. Such strategies apply in digital markets and a broader context, more granular sometimes when it comes to markets based on SMEs. The notion of digital markets may produce the impression

\footnotetext{
${ }^{2}$ We can consider that the integration within an ecosystem can be analysed as a partnership between a keystone and a firm who's proposing complementary services and product. It is then possible to rely on the management sciences originated literature (see for instance on the Apple's innovation ecosystem, Granstrand and Holgersson, 2020).

${ }^{3}$ See Fisher-Ellisson (2016) for a literature review.
} 
that some other markets are not digital. It also implicitly creates the impression that an analytical framework based on market share (quantity) and the degree of contestability is still adequate for these new markets, impacted by the Industrial Revolution that we are living through. Thus, a further contribution is about the real paradigm shift: market dominance should not be analyzed anymore in algorithm-based markets through the lens of market share but should use another instrumental variable: information.

The case of E.U. Commission initiatives in the domains of algorithms-led markets is fascinating to consider under this perspective. First, the statement of objections notified in October 2020 to Amazon is based on the absence of a level playing field between Amazon and its complementors/competitors regarding information access. ${ }^{4}$ Secondly, the regulation published in June 2019 related to the transparency and the fairness in P2B relationships highlights the importance of unequal access to information as a source of competitive bias in the competition in the market (in case of self-preferencing practices). In this dynamic, the Commission recently issued (in December 2020) a new regulation aiming at increasing transparency in matters of ranking. ${ }^{5}$ Thirdly, as underlined above, the DMA emphasizes the competitive consequences of unequal access to information among the stakeholders of each digital ecosystem and its consequences in matters of competition between ecosystems by impairing the capacity of complementors to multi-home or to exert an exit option from a given ecosystem.

The essential point is to connect the information imperfections (e.g. the absence of an informational playing field) with the impairing of the competition for the market) and with the development of a distorted competition within the market (e.g. in each ecosystem).

The purpose here is not to describe all the DMA proposals regarding informational bias but only to provide some examples. Self-preferencing is one of the E.U. Commission's primary concerns. It can be observed when the platform has a dual role, e.g. when its vertical integration leads the keystone to compete with its complementors. A similar case can be observed when a keystone privileges one complementor vis-à-vis its competitor since it had accepted to pay for ancillary services or enter an exclusive contract. Self-preferencing is easier to implement that the access to information is incomplete and asymmetric. ${ }^{6}$

Our contribution is twofold: first, we propose a formal analytical framework to understand the issues highlighted by the E.C., and second, we assess the propositions put forward by the DMA.

Political regimes, such as democracies, have multiple institutions to make sure they operate efficiently and fairly. Before the A.I. revolution, markets had one institution: the price mechanism. From an Industrial Organization perspective, Competition Law was about making sure this institution provided efficiency and fairness to the competitors. The invisible hand was sometimes nudged. In digital platforms, some firms may become keystone players (in management language) or gatekeepers. If they become too big, they may replace the invisible hand and the price mechanism.

\footnotetext{
${ }^{4}$ EU Commission, "Antitrust: Commission sends Statement of Objections to Amazon for the use of non-public independent seller data and opens second investigation into its e-commerce business practices", Press Release, 10 November 2020 , cases AT.40462 and AT.40703, IP/20/2077

${ }^{5}$ EU Commission, "Commission Notice Guidelines on ranking transparency pursuant to Regulation (EU) 2019/1150 of the European Parliament and of the Council", 2020/C 424/01, EU Official Journal, 8 December 2020, pp. C424/1 - 26

${ }^{6}$ See pt. 43 of the EU Commission DMA: "To prevent gatekeepers from unfairly benefitting from their dual role, it should be ensured that they refrain from using any aggregated or non-aggregated data, which may include anonymised and personal data that is that is not publicly available to offer similar services to those of their business users".
} 
As a result, they replace the institution that makes the markets work. It is not inherently wrong, and in many ways, it has created a wealth of innovation and has augmented the market's overall surplus.

This A.I. revolution has unprecedented positive impacts on our societies from a technological perspective and a market operations perspective. We all enjoy Google Maps, Uber Eats, Amazon, etc. The world is a better place for consumers who have access to these technological offers than the past alternative. However, the fact that a keystone may become the market institution has consequences. The first one is that it can control the market and capture the whole consumer surplus. The second one is that it creates private regulations.

This legal creation is done through contractual agreements imposed by the keystone. It is the law of the parties, but it is also a nuanced law of the parties as one of the market players enjoys a superior bargaining power and can impose its contractual provisions (Bougette and al., 2019) unilaterally. Only one firm creates regulations on the market. Hence, a market can be regulated by a firm's rules production to the best interests. This is a violation of one of the main principles of the law. Private interest-based regulation is at odds with the principles of free and undistorted competition and competition requirements on the merits.

Why may we observe in such a situation? This is where technology enters. Keystones' technology allows these firms to collect and create market-relevant information. They serve as the visible hand. They are the coordination mechanism that the price mechanism was playing. The difference is that the price mechanism provides an aggregated equilibrium price on the market, resulting from the confrontation between the overall demand and supply. In the case of a keystone, it knows everything (if we push the argument to the extreme) at the aggregated and unit level (the consumers). Hence, as an 'entrenched' dominant player, it collects and creates information with its own bias. As a result, a market may end up inefficient (X-inefficiency) and unfair. We may still benefit from the status quo in terms of technological innovations, but we may not benefit from the next great leap that would have been possible on a more competitive market where the price mechanism driven by the (politicallyregulated) invisible hand would have still be the leading force at stake.

The paper is structured as follows. Its first section develops a short literature review and insists on the asymmetries among ecosystems' stakeholders. The second section analyses such relationships under the length of information. The third section presents our model. its shows the increasing capacity of the keystone to exploit its informational advantage to the detriment of its complementors. The fourth section discusses its results in the E.U. Commission DMA context and of the complaint against Google's practices in the advertising market in the U.S. Section five concludes and opens some paths for future research.

There is another dimension to our discussion here: indeed, we want to stress that the core instrument here is not the technology but the information. The technology is unique in human history, but it only allows keystones to grasp (with no malice) crucial market players' information. In what follows, we will build our case around this hypothesis we make: information is the ultimate instrument. We will also build our case for the theory we propose for the new Competition Law principles built around information analysis. It is no longer about market shares or contestability (which is still about market shares), but about who controls market information.

\section{Literature review}

First, let us go over a definition exercise. It is essential to make the distinction between gatekeepers and keystone players. Gatekeepers have first designed the algorithms and have created a lock-in 
situation through contracts or technical dependencies. As a result, they may dominate a market in the traditional sense. Second, gatekeepers may also dominate the market by hierarchically controlling the other firms when they lock-in the complementors. What was called a partner in the context of vertical integration is now called a complementor in this context.

A keystone is a platform-based firm that accelerates innovation and productivity in unprecedented ways thanks to using the latest technologies (machine learning and big data, recommender systems, etc.) (Marty and Warin, 2020a). At some point, by using some strategies highlighted in the DMA, keystone players may become gatekeepers.

In the following table, we propose some definitions. An important aspect to consider here is the tentative reconciliation we propose across disciplines. Indeed, we use different concepts from multiple disciplines and try to benefit from their subtleties to develop a more precise dictionary. By tapping into each relevant domain and its definitions based on its context, we can build an efficient taxonomy, capturing a more comprehensive analytical framework.

Table 1. Algorithm-based markets taxonomy.

\begin{tabular}{|c|c|c|c|}
\hline Law & Concepts & Definitions & Domains \\
\hline \multirow[t]{2}{*}{$\begin{array}{l}\text { Competition } \\
\text { Law }\end{array}$} & Keystone & $\begin{array}{l}\text { a pivotal firm in an ecosystem - event if } \\
\text { this one does not enjoy a dominant } \\
\text { position, it can exert a structuring power } \\
\text { upon its ecosystem }\end{array}$ & $\begin{array}{l}\text { Management } \\
\text { Science }\end{array}$ \\
\hline & Gatekeeper & $\begin{array}{l}\text { According to the EU DMA, a keystone can } \\
\text { be considered as a gatekeeper when it } \\
\text { - has a strong economic position, a } \\
\text { significant impact on the internal } \\
\text { market and is active in multiple E.U. } \\
\text { countries } \\
\text { - has a strong intermediation } \\
\text { position, meaning that it links a } \\
\text { large user base to a large number of } \\
\text { businesses } \\
\text { - has (or is about to have) an } \\
\text { entrenched and durable position in } \\
\text { the market, meaning that it is stable } \\
\text { over time }\end{array}$ & $\begin{array}{l}\text { Competition } \\
\text { Law }\end{array}$ \\
\hline \multirow[t]{2}{*}{$\begin{array}{l}\text { Contractual } \\
\text { Law }\end{array}$} & Partner & $\begin{array}{l}\text { It echoes the management science-based } \\
\text { literature on long term partnerships as } \\
\text { joint-ventures }\end{array}$ & $\begin{array}{l}\text { Industrial } \\
\text { Organization/ } \\
\text { Economics }\end{array}$ \\
\hline & $\begin{array}{l}\text { Compleme } \\
\text { ntor }\end{array}$ & $\begin{array}{l}\text { It echoes the literature on ecosystems (see } \\
\text { Gawer and Cusumano, 2002, for instance) }\end{array}$ & $\begin{array}{l}\text { Competition } \\
\text { Law }\end{array}$ \\
\hline
\end{tabular}


In the following graph, we complement Marty and Warin (2020c) by mapping the inflection point between the keystone and the gatekeeper regarding the market's innovation rate. It is in line with the DMA's point 63:

Following a market investigation, an undertaking providing a core platform service could be found to fulfil all of the overarching qualitative criteria for being identified as a gatekeeper. It should then, in principle, comply with all of the relevant obligations laid down by this Regulation. However, for gatekeepers that have been designated by the Commission as likely to enjoy an entrenched and durable position in the near future, the Commission should only impose those obligations that are necessary and appropriate to prevent that the gatekeeper concerned achieves an entrenched and durable position in its operations. With respect to such emerging gatekeepers, the Commission should take into account that this status is in principle of a temporary nature, and it should therefore be decided at a given moment whether such a provider of core platform services should be subjected to the full set of gatekeeper obligations because it has acquired an entrenched and durable position, or conditions for designation are ultimately not met and therefore all previously imposed obligations should be waived.

In Marty and Warin (2020c), we have shown that the structuring of an industry in an ecosystem has a specific impact on the innovation path. The impact on innovation incentives and capacities is always positive even when the keystone's dominance is entrenched (i.e. after tipping). However, the curve increases very quickly at the beginning (due to the sharing of risks, resources, etc.), then increases at a decreasing rate and finally decreases (the capacity to innovate is strong, the incentives are increasingly weak but never negative due to the risks of disruption and the need to preserve and develop the data flows necessary to train the algorithms, etc.).

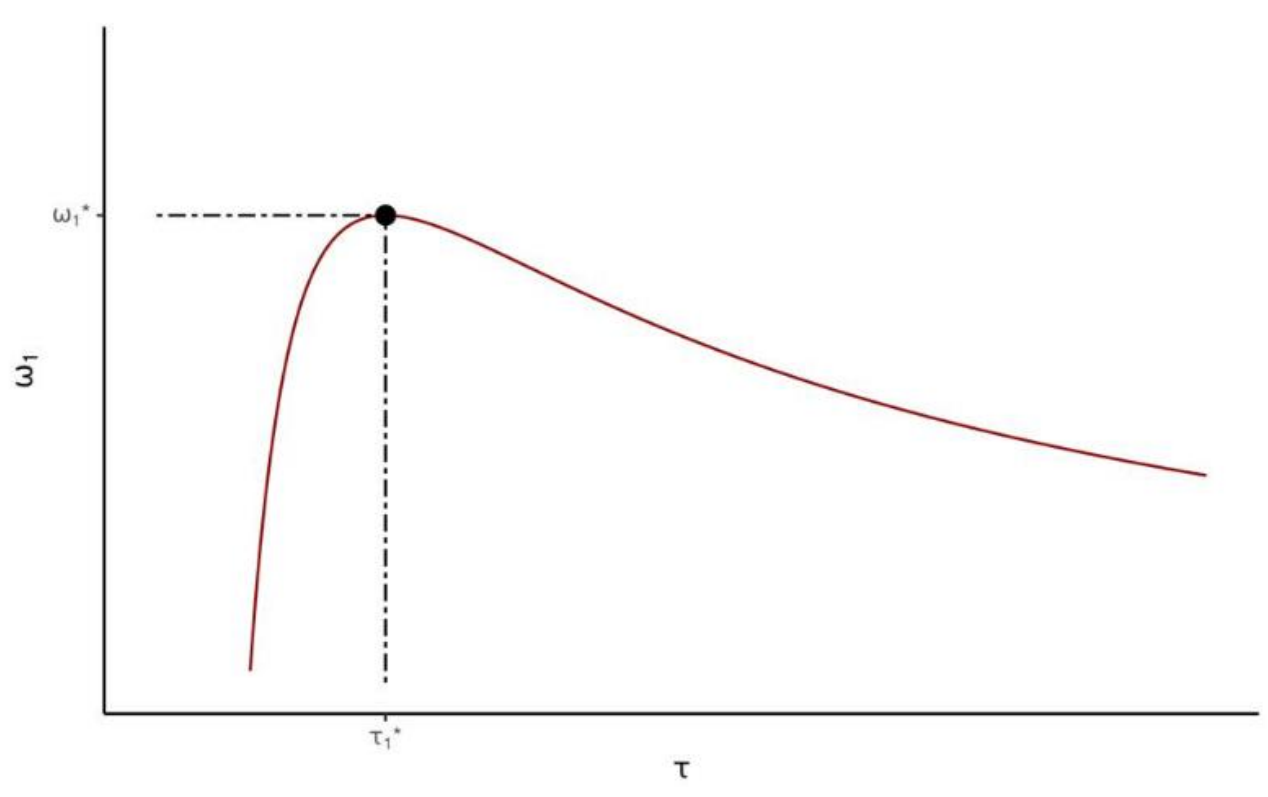

Figure 1. Innovation rate of a keystone player (Marty and Warin, 2020c).

Our paper represents the same kind of dynamic but from a different perspective; we are not talking here about the keystone's capacities/incentives to innovate according to the duration of the "partnership" but about the keystone's capacity/incentives to share the surplus with its complementors in function of the duration of the partnership. The part of the surplus that the 
complementor can extract is always positive, but the part to which it can claim decreases with the duration of the partnership; in other words, the more "locked" the complementor is, the more it is treated as a tourist and not as a native.

While in the models used in the field of consumption, the native is better treated over time because accumulating experience reduces its information deficit, in our model, it is the opposite: the longer the partnership is, the less information the complementor has at its disposal to know the characteristics of its users and the less it can compare with a counterfactual. Its stock of information is not increasing but decreasing over time. This informational deficit (among other elements) impairs its capacity to capture a fair share of the positive surplus resulting from the ecosystem's integration. The partnership does not generate informational gains that help the complementor limit its disadvantage toward the keystone progressively. On the contrary, the longer the partnership's duration, the higher the level of information incompleteness and asymmetries.

The captive complementor is more and more naive and becomes a "tourist" without knowledge of the market's actual conditions. Its situation contrasts with the one of a multi-homer complementor that enters the ecosystem and can easily benchmark with the conditions proposed by other keystones. So the capacity of the complementor to benefit from its integration in an ecosystem should be initially important and characterized by increasing trend (because of the incentives provided by the keystone to opt for mono-homing and to reward its loyalty). Nevertheless, beyond a given threshold from which the effects of economic and technological dependences locked-it in the ecosystem, its share of the surplus decline progressively.

\section{Integration in digital ecosystems and access to information}

Before presenting our model, it can be relevant to come back to the E.U. Commission DMA and some competition law-based litigations to illustrate the hypothesis of an increasing informational disadvantage of ecosystems' complementors leading to an unbalanced sharing of the surplus created by the partnership.

\section{Reflections from the E.U. Commission DMA}

The E.U. Commission's DMA insists on the competitive consequences of unbalanced and unfair P2B relationships resulting from economic or technological dependence observed in ecosystems. These issues can be stressed not only in the case of an absolute dominance on a given relevant market -as commonly defined in competition law enforcement - but also in a case of a relative dominance on a given ecosystem.

The relative dominance depends on several factors like the intensity of the competition among ecosystems and the barriers to exit from an ecosystem for a complementor. The lower the intensity of the competition (because of an industry structuring in vertical silos, for instance) and the higher the switching costs, the higher the dependency. This dependency can be built or enhanced by the keystone strategy through several channels (Marty and Pillot, 2019). First, the resources initially provided to lower the barriers to entry in the ecosystem (APIs, data ...) also play a role in barriers to exit as they are specific to the technology of the keystone and the complementary devices owned by the users. Secondly, the complementors have imperfect access to data ${ }^{7}$ (even their users' data) on

\footnotetext{
${ }^{7}$ The opacity is not limited to the data they generate but also exists regarding the performance of the services they use. It is for instance the case in the publishing and in the advertising industries. See the article 6-1-g of the DMA : "[the gatekeeper
} 
the platform - in case of exit - they renounce to access and port these; consequently, the higher the turn-over realized on a platform, the higher the cost of the exit option. Thirdly, the complementors have to realize specific investment whose value or whose quality in technical terms depends on specific assets or complementary resources controlled by the keystone or by other complementors; the more developed the integration in the ecosystem, the higher the cost of the exit option.

Consequently, considering the gains of the integration in an ecosystem, the complementors have a direct interest in opting for the higher level of integration and the higher duration of the partnership. It results from these points in a higher dependency. The keystone itself has all the reasons to lock its complementors in its ecosystem: the reasons can be searched to maximize the gains resulting from complementary investments, reducing the risks related to investments, maximizing the diffusion speed of innovations, and collecting data.

These pro-efficiency claims are not solely considered; the keystone is directly interested in incentivizing its complementors to a single home. It makes the ecosystem essential to some users on the second side of the platform, as they cannot find the same services on another one. It raises the costs of exit for complementors as the other ecosystems have certainly developed competing services.

The platform has all the reasons to encourage single-homing strategies through incentives and retaliations. The first one can be marketplaces' participation in consumers fidelity programs (Amazon Prime, BuyBox, Amazon's choice...). The second one can consist of risks to be challenged by other complementors more cooperative, to see your products cloned, to endure automatic price decreases, to be delisted, to see your ranking manipulated.

The paradoxical consequence of loyalty is an increasing dependence and a dramatic drop in terms of bargaining power (and the capacity to exert a countervailing market power). It results from this dependence a decreasing capacity to obtain a fair share of the transaction surplus. A vicious circle can be described. A decreasing margin also implies a weaker capacity to pay for exiting and a weaker capacity to invest and to innovate that induces a higher probability to see your product cloned or to be supplanted by a competing complementor that represents more promising capacities for the keystone).

However, our prism is not based on resources related issues but on the information. As the E.U. Commission's November 2020 lawsuit against Amazon shows, not only the complementors could be obliged to act according to the keystone's interests to become and to remain a first-rank partner, but the information that the complementor extracts from its operations in the ecosystem is asymmetrical and incomplete.

We can stress an information-based paradox of partnerships between complementors and the keystone in digital ecosystems: the longer the partnership's duration and the higher its intensity (exclusivity provisions), the more critical the informational disadvantage.

In games theory-based approach, a new entrant in an ecosystem can be seen as a tourist: it has to accumulate returns of experience and to build a reputation to be seen as a native and to benefit from better transaction conditions - e.g. to be positively discriminated-. In other words, fidelity pays. We could also consider that the keystone has the interest to reward the loyalty (e.g. the single homing

shall] provide advertisers and publishers, upon their request and free of charge, with access to the performance measuring tools of the gatekeeper and the information necessary for advertisers and publishers to carry out their own independent verification of the ad inventory". 
decision) and sanction multi-homers that do not provide any competitive advantage (in terms of differentiation) against other ecosystems.

\section{An application to digital advertising markets}

However, neutralizing the competition for the market can be facilitated by single-homing. As soon as the vertical silos become sealed, the keystone has less reason to guarantee a fair competition within the ecosystem and can benefit from its increasing informational advantage against its loyal complementors. It can engage such strategy to increase its margin or to subsidize new entrants to lower the barriers to entry to its ecosystem or to discriminate for their profits in order to deprive competing ecosystems of the gains associated with exclusivity (for the users on the other sides of the platform) or to benefit from new data sources.

An additional example of the consequences of artificial opacity in P2B relationships can be provided by the complaint filed by several U.S. States attorney general against Google LLC before the U.S. District Court of Eastern District of Texas (civil action ${ }^{\circ} 4: 20$ cv957, filed 12/16/2020). The complaint deals with Google practices in the advertising market and - among other concerns consider that the firm had monopolized this market through self-preferencing strategies. Our purpose here does not consist of analyzing the full complaint and giving any opinion on its soundness ${ }^{8}$. We aim to insist on access to information for the stakeholders that use exclusively the tools provided by the keystone. In that case, Google's market position makes it an "unavoidable middleman" in the market. As the complaint states: "In addition to representing both the buyers and the sellers of online display advertising, Google also operates the largest exchange AdX. In this electronically traded market, Google is pitcher, batter, and umpire, all at the same time" (pt. 4). This position is even more entrenched that the only possible technological alternative had been cornered by (alleged) anticompetitive practices and by a possible "predatory innovation" developed by the keystone.

Digital advertising markets are as complex as financial markets and may appear even more opaque, mainly because of the absence of a sector-specific regulation (Srinivasan, 2020).

Not only "in this complexity, the market for display ads resemble the most complicated financial market: publishers and advertisers trade display inventories through brokers and on electronic exchanges at lightning speed" (pt. 3), but also the dominant player - the gatekeeper - would have implemented opacifying strategies.

First, a specific program developed by the keystone (Enhanced Dynamic Allocation - EDA) would have to prevent publishers to directly sell their "higher value inventories" to advertisers (pt. 144). The implementation of this program prevents the publisher from bypassing its "auction mechanism." All the exchanges are channelled toward the system. It is no longer possible to run specific auctions for premium impressions. As direct deals become impossible, the publishers are increasingly in a disadvantaged information position vis-à-vis the gatekeeper. One of the main consequences of such an "exclusivity" is that the market price disappears, and all transactions can be made at a hypothetical price calculated by Google (pt. 148). The invisible hand is replaced by intelligent handling of competition but without a guarantee that the gatekeeper acts benevolently. We are not in a similar situation that the one of a stock-exchange for two main reasons. First, prices are all but transparent. Second, as the complaint states, the same company owns the largest buy-side and sell-side brokers and the monopoly stock exchange (pt. 5). In other words, the vertical integration of the keystone (its dual role) raises self-preferencing related concerns. This lack of transparency would have a direct

\footnotetext{
${ }^{8}$ See Geradin and Katsifis (2019) for a discussion.
} 
impact in terms of keystone's capacity to manipulate market decisions ("to cherry-pick the valuable impressions," pt. 149), leading to an unfair sharing of the transaction surplus.

According to the complainants, this strategy also relies on maneuvers crippling publishers' ability to measure header-bidding success (e.g. the only alternative to the keystone's exchange platform). As soon as the results of this alternative have been made "unobservable and unmeasurable" (pt. 204), the "captive" complementors cannot use any benchmark to assess the relative performance of the keystone's services. This effect is enhanced by obfuscating strategies (pt. 219) that make prices imperfectly observable. The complaint insists on the process that induces an increasing dependence of the publishers. First, Google's gatekeeper position leads the publishers to abandon the control of the contents (they are owned), leading it to extract a disproportionate share of wealth. Second, its structuring power on the ecosystem (its private regulator power) allows Google to select technologies that made it an unavoidable trading partner and voluntary obfuscates the market price signal. This selection can be implemented by pushing proprietary technologies (see the AMP case) or hindering technologies that may reduce the platform users' informational disadvantage. The case of the cookies ban ${ }^{9}$ is seen under this prism by the complainants: "Google's decision to phase out thirdparty cookies on Chrome only increases the information asymmetries, leaving publishers with fewer alternatives other than Google's user data" (pt. 228).

A very last point should be put into relief: the claims in the complaint are grounded on the Sherman Act but also on "false, deceptive, or misleading acts or practices." According to the plaintiffs, "[...] Google at least implicitly misrepresents that it is operating in the best interest of its customer, fails to disclose its conflict of interest, and misrepresents the many ways that Google operates to disadvantage its customers" (pt. 335).

Google's case is all the more relevant for our purpose that it illustrates as a gatekeeper that exerts a structuring power can act in a non-cooperative way toward its dependent complementors, privileging "the tourists" against "the natives." Not only, the first ones bring an additional value in strategic terms (to attract new complementors and to propose them an exclusive contract), but the second ones cannot exert any exit option first because of their technical and contractual dependencies and second because of their increasing lack of data allowing them to measure how unbalanced the contractual terms dictated by the keystone are. Our purpose is that the information disadvantage of a captive trading partner increases with its duration with the keystone and its technical dependency toward its technology. The deeper the technical integration, the lower the capacity to capture any undistorted market signal. In other words, the integration in an ecosystem may insulate the complementor from market originated price signals. Its coordination with other ecosystem players will be ensured only through contractual terms or keystone's calculated hypothetical prices (pt. 148). The gatekeeper is not only the commissaire priseur (auctioneer) but also a market player. Its market regulation can be easily a private-interest one because of both the inherent complexity of digital markets in terms of price signals and the keystone's capacity to engage obfuscation strategies.

\section{Model}

The model highlights the vacuum effect generated by a multi-sided platform that integrates and concentrates its complementors' information. The model clarifies that this vacuum effect (the result

\footnotetext{
${ }^{9}$ See also Geradin and Katsifis (2000) for a discussion.
} 
of the multi-sided platform's inner dynamics in terms of information concentration) has replications on the overall market (the Competition Law domain). This article wants to model the platform dynamics - inside and outside - and better understand the implicit assumptions that we find in new proposed regulations such as the DMA. A game theory model is interesting to capture the role of information. It helps capture the complexity and dynamics of the various interactions. This model's foundations are from Carlton and Perloff (2005), where they design the competition dynamics between stores trying to sell to consumers that are either tourists or natives. We are inspired here by their simple and elegant framework. We believe it helps bridge the expert conversations on machine learning and algorithms with the legal conversations. It is an efficient translator from the live equilibria generated by algorithms to the legal implications. Elegant models in game theory are also easily accessible for people who are not versed in mathematical formalization. We augment and adapt Carlton and Perloff's (2005) 's model to our purpose by considering two layers of analysis: the first one being the competition between platforms and the second one being about the information concentration between platforms and their complementors.

\section{Hypotheses}

Let us introduce now the share of informed versus uninformed complementors.

The hypothesis is that informed complementors have control over their technological capacities and their value chain. They are larger platforms that contract with a platform initially to benefit from its multi-sided properties. On the other side of the spectrum, the uninformed complementors are small and medium enterprises that do not have technological capacities. They go to a platform to benefit from its multi-sided properties, and mostly to its technology (servers and recommendations' system).

The informed complementors keep some control of their information and feed the platform (initially) with minimalist information. The uninformed complementors provide all their information and benefit from the platform's value-added (logistics, analytics, recommender system).

Of the $L$ complementors on this market, the informed complementors represent a market share of $\alpha L$, and the uninformed complementors represent a market share of $(1-\alpha) L$. Among the uninformed complementors, there is a $\mu$ share that has a less inelastic demand than the other $1-\mu$ share of the uninformed complementors.

The multi-homing cost for complementors is defined as $\theta$. It corresponds to:

$$
\theta=\delta \sigma
$$

with $\delta$ capturing the search cost to find a better platform, and $\sigma$ representing the switching cost. The latter can be defined as a function of the pure cost of adding another platform, $\eta$ and the cost of exiting a platform, $\gamma$, with:

$$
\sigma=\eta \gamma
$$

with $(\theta, \sigma, \eta$ and $\gamma) \in \mathbb{R}^{+}$.

Each complementor buys 1 unit of the platform' service as long as the price is no higher than $p^{u}$ (price for the uninformed).

There are $n$ platforms on this market, with $n=[1, \infty]$. Moreover, we define $n$ as a function of the market share dynamics of the various platforms to capture this precise endogeneity. 


\section{Stage 1}

On a competitive market, several platforms exist, and all platforms set the same price $p^{c}$, which is the competitive equilibrium price, and each is assumed to obtain an equal share of the complementors, so it sells $q^{c}=L / n$ units of platform service.

The pure and perfect competition equilibrium quantity, $q^{c}$, is equal to the minimum of the average cost curve, where $q^{c}$ is equal to the average cost and the marginal cost, $q^{c}=A C=M C$.

Suppose that a deviant platform raises its price to $p^{*}=p^{c}+\epsilon$. The platform obtains no informed complementors since their demand is perfectly elastic. The platform still gets its share of uniformed complementors, as long as $\epsilon<\theta$, since their demand is inelastic.

In this context, the platform's sales fall to $(1-\alpha) L / n$.

If there are many informed complementors, it does not pay for a platform to deviate by raising its prices above $p^{c}$. If there are enough informed complementors, all complementors are charged the full information, competitive equilibrium price. Again, here the role of information is central to our proposed theory.

When the multi-homing cost is positive, let us suppose that each uninformed wants to pay a maximum price of $p^{u}$. The informed do not want to pay more than $p^{c}$.

The platform will charge $p^{u \prime}=p^{u}-\theta$ to the uninformed, but the informed need to remain informed, otherwise through time, the information concentration will accelerate for them due to the technological attractiveness of the platform and $p^{c}$ will rise by a factor called $\psi$. So, $p^{c \prime}=p^{c}+\psi$.

Only the uninformed will buy; hence the total revenue is $R^{u}=p^{u \prime}(1-\alpha) L$ for the uninformed.

\section{Stage 2: Competition dynamics on the platform market}

Let us now study the competition dynamics among platforms through the price mechanism. Let us see the price and market share adjustments resulting from this price-based competition. Competition on a platform-based market is slightly different as complementors have multiple options: (1) they can decide in favour of single-homing for platform A, for instance, (2) they can decide to switch to the competitor, namely platform B, also through single-homing, (3) they can decide in favour of multihoming, which means they will deal with both platforms, or (4) they can decide to be their platform.

At this stage, platforms can decide to charge different prices, as the invisible hand would tell us. This leads in this case to the following total revenue:

$$
R^{u}=p^{u \prime}(1-\alpha)(1-\mu) L+p^{c \prime} \alpha L+p^{c \prime}(1-\alpha) \mu L
$$

In the previous equation, the informed will pay $p^{c \prime}$ and no more. However, some uninformed - the ones that are in the less inelastic group - $\mu$ out of $(1-\alpha) L$ - will go to another platform or perform some multi-homing strategies and pay $p^{c^{\prime}}$, while the others $(1-\mu)$ out of $(1-\alpha) L$ will still pay the uninformed price $p^{u \prime}$.

If there are relatively few informed complementors, a deviant platform can raise its price.

Let $q^{a}$ be the quantity such that $A C\left(q^{a}\right)=p^{u}$, as in $A R=A C$, the optimization rule.

It pays for a platform to deviate if $q^{u}>q^{a}$ with $q^{u}=(1-\alpha)(1-\mu) L / n=(1-\alpha) q^{c}$. From there: $\alpha=1-\frac{q^{a}}{q^{c}(1-\mu)}$. 
At $q^{u}$, the deviant platform's average cost is less than $p^{u \prime}$, so it makes a profit if it charges $p^{u \prime}$.

In the two-price market situation, the low-price platforms charge $p^{c \prime}$ and sell $q^{c}$ and have $\beta$ share of the market, while the high-price platforms charge $p^{u \prime}$ and sell $q^{u}$. Moreover, it makes up $1-\beta$ share of the market. We realize here that $\psi$ is a function of $\beta$. The hire $\beta$, the lower $\psi$. The high-price platforms only sell to their share of the $(1-\alpha) L$ uninformed complementors,

$(1-\alpha) L(1-\beta)$, so each high-price platform sells:

$$
q^{u}=\frac{(1-\alpha) L(1-\beta)}{n(1-\beta)}=\frac{(1-\alpha) L}{n}
$$

The high-price platforms' market share is:

$$
1-\beta=\frac{q^{u}}{L}=\frac{1-\alpha}{n}
$$

Each low-price platform sells to its share of the $\alpha L$ informed complementors and to its share of the $\beta(1-\alpha) L$ uninformed complementors who are among the less inelastic group:

$$
q^{c}=\frac{\alpha L+(1-\alpha) \mu L \beta}{n \beta}
$$

The market share of a low-price platform is thus:

$$
\beta=\frac{q^{c}}{L}=\frac{\alpha+(1-\alpha) \mu \beta}{n \beta}
$$

In equilibrium, the low-price platforms get all the informed complementors and some of the uninformed complementors, so their share of the market is greater than the proportion of informed complementors: $\beta>\alpha$.

Let $q^{a}$ be the quantity at which average cost equals $p^{u \prime}$. That is, $q^{a}=q^{u}$, so that

$$
q^{a}=\frac{(1-\alpha) L}{n}
$$

Similarly, $q^{A}$ is the quantity at which average cost equals $p^{c \prime}$, so $q^{A}=q^{c}$, and:

$$
q^{A}=\frac{\alpha L+(1-\alpha) \mu L \beta}{n \beta}
$$

Equations of $q^{a}$ and $q^{A}$ are equations in two unknowns, $\beta$ and $n$. Rearranging the equation of $q^{a}$ yields:

$$
n=\frac{(1-\alpha) L}{q^{a}}
$$

Substituting from the equation of $n$ into the equation of $q^{A}$ and rearranging terms,

$$
\beta=\frac{\alpha q^{a}}{(1-\alpha)\left(q^{A}-\mu q^{a}\right)}
$$

The two-price equilibrium is characterized by $n$ and $\beta$ (determined by the equations above). The $\beta n$ low-price platforms sell $q^{A}=q^{c}$ units at $p^{c \prime}$ and $(1-\beta) n$ high-price platforms selling $q^{a}=q^{u}$ at $p^{u}$.

As a result, when platforms concentrate their complementors' information as time passes, the inelasticity level rises and: $\mu, \alpha$ and $\beta$ decrease. As a result, the high-price platforms' market share $(1-\beta)$, rises, and $n$ decreases.

The model demonstrates that information is the instrumental variable here (Warin and Leiter, 2012). A competition in price is ineffective to capture some market share. The information concentration 
dominates a competition in price. The price mechanism does no longer play its role in this context of price-discrimination strategies in platform-driven markets. The adjustment variable is market share (quantity) as a result of the information concentration.

Another relevant conclusion is the rise in the information concentration cost, represented by $\psi$. It leads to $p^{c \prime}$ getting closer to $p^{u \prime}$, and amplifying the drop in the value of $\beta$.

As a result, multiple forces are at stake and may lead a platform to go from a keystone player to a gatekeeper, just out of strategic and irresistible inner dynamics.

\section{Discussion and lessons for Competition Law}

We stress in this paper the informational paradox of long-term relationships in digital ecosystems. The longer the partnership's duration and the higher its exclusivity level, the more critical the informational vulnerability of the complementors. The market will be less and less transparent for the complementor (its data "stock" is a decreasing one both in quantity and quality), and it knows itself less and less just because of the asymmetrical access to the data related to its customers and to the transactions it induces on the platform.

The E.U. Commission DMA dos and don'ts can be analyzed under this prism. Its dos and don'ts could be analyzed under this prism.

Let us first consider the dos. Data portability, access to data (not only collected one, but also observed and deduced ones (see pt.55), or interoperability requirements can be seen as resources to limit information disadvantages and reduce the costs associated with the exit option for the complementor. The objective is twofold: reducing information asymmetries and incompleteness and lowering the exit barriers. ${ }^{10}$

The same purpose can be put into relief for the don'ts. It is a matter of preventing strategic asymmetric use of data-based advantages for the keystone (as self-preferencing).

The purpose is to prorogate the "tourist" statute of complementors. Two gains are searched for. The first one is to preserve a given degree of competition between ecosystems - competition for the market. The second one consists of equilibrating the conditions of the competition within the market (in the ecosystem) by limiting the informational disadvantage of loyal complementors

In terms of competition policy requirements, it is possible to interpret regulations as the E.U. Commission's DMA under information prism.

It is not an issue of sanctioning keystones for their success. It is no more an issue of reshuffling cards. It is an issue of enhancing market fluidity (reducing costs of exit - e.g. switching costs by considering that information can play an essential role in economic dependence) and avoiding excessive concentration or excessively unbalanced contractual conditions within the ecosystems, increasing the information accessible to complementors. The better informed the complementors are, the less dependent and the more performant they will be.

\footnotetext{
10 "Business users that use large core platform services provided by gatekeepers and end users of such business users provide and generate a vast amount of data, including data inferred from such use. In order to ensure that business users have access to the relevant data thus generated, the gatekeeper should, upon their request, allow unhindered access, free of charge, to such data".
} 
Some of the provisions proposed by the DMA aims at tackling these issues. We have already quoted the art. 6-1-g proposes to grant publishers and advertisers access to performance measuring tools related to their contents and advertising campaigns. We could also stress the $6-1-\mathrm{h}$ and the $6-1-\mathrm{i}$ proposes to impose the provision to the complementors of continuous and real-time access to the data generated by their activities. ${ }^{11}$

The history of economics and the history of case law offer to us striking examples of such debates one century ago in another industrial revolution. Despite the considerable differences in available technologies, the USA's situation in the early 20th century echoes our current concerns. The relationships between the trusts, the chain stores... and the independent firms were also analyzed under the prism of economic dependence and not under efficiency. We can further on this path and insist that according to some scholars as Robert Lande (1982), the Sherman Act aims to prevent undue wealth transfers. It was a matter to promote the "normal" functioning of the market not in terms of efficiency but terms of surplus sharing.

These debates on the purpose of antitrust can also be considered under the prism of the interpretations produced by contemporaneous thinkers and lawyers as Louis Brandeis, who became associated justice in 1916 (Bougette and Marty, 2020). In Louis Brandeis' views, the Sherman Act should prevent economic concentration. However, Section 1 prohibits all information exchanges between competitors. In the 1910s and 1920s, many structures as trade associations, open price associations or fair-trade leagues organized information collection, treatment and sharing among their members in order to help them to make better-informed decisions (mainly to avoid price wars, to counteract informational deficit vis-à-vis powerful downstream or upstream unavoidable trading partners). The U.S. Supreme Court used to sanction these arrangements whatever the enterprises at stake and whatever their actual effects on the market. ${ }^{12}$

The case law reversal was very striking with Maple Flooring in $1925 .^{13}$ Since the information exchange is organized among small players, without any collective capacity to be a price maker and is freely accepted, the practices should not be systematically sanctioned under Section 1 . This position was advocated 4 years earlier in a former judgment American Colum by two dissents, one written by Justice Holmes, one other by Justice Brandeis. According to Holmes, the better informed the market players, the more efficient their choices - as a consequence, antitrust laws have not to hinder information exchange, diffusion or efforts to make the market more transparent. According to Brandeis, a "competition on the merits," a "level playing field" (to use our current vocabulary) is impossible as soon as the market players do not access the same information to ground their decisions. As a consequence, trust is always advantaged compared to a small partner. It is legitimate to authorize them to exchange data to equilibrate their information set.

\footnotetext{
${ }^{11}$ The Commission also disposes of other tools to avoid an asymmetrical access to data that can distort competition. It is the case in mergers control. The clearing of the acquisition of Fitbit by Google is conditioned to corrective measures as a thirdparty access to data generated by Fitbit or the constitution of "data silos" consisting in a technical separation of the data produced by Fitbit activities and the ones from Google. See European Commission decision, case M.9660, December 2020. It worth noting that the keystone may enhance its informational advantage by acquiring complementors and new lines of business in adjacent markets. The broader the diversification, the higher the data advantage upon the complementors / competitors in current and future market segments.
}

\footnotetext{
${ }^{12}$ American Column \& Lumber Co. v. United States, 257 U.S. 377 (1921)

${ }^{13}$ Maple Flooring Manufacturers' Assn. v. United States, 268 U.S. 563 (1925)
} 
In 1920 in the U.S. Supreme Court judgment FTC v Gratz, Brandeis made a very similar analysis of the 1914 FTC Act's legislative intent. ${ }^{14}$ According to him, the Commission has to spread market data on the whole market (Herbert Hoover had roughly the same view) and address unfair trade practices (Section 5 of the Act) that can result in information imperfection.

What is the sense of these claims and these legal initiatives? To cope with data-advantages and to allow better access to data in order a) to maintain the conditions of the competition for the market and b) to ensure the information requirements of fair competition within the market.

It is the same idea from an industrial revolution to another one. It is not an issue of limiting the size of the gatekeepers (big firms one century ago), dismantling ecosystems (trusts one century ago) and ensuring a levelled access to information.

The formal framework we highlight here stresses the importance of the core instrumental variable: information. Who controls information - the market information - controls the market. As a consequence, the firm in such a position enjoys a rising monopolistic power.

This framework - we believe - allows us to understand the inner dynamics within algorithm-based markets. It highlights the two dimensions that occur nowadays: first, leading firms (defined as firms having designed the algorithms first and having de facto or de jure created a lock-in situation) may dominate a market in the traditional sense. This is thus the domain of Competition Law regulators. Second, leading firms may also dominate the market by hierarchically controlling the other firms the vertical integration of partners - when they lock-in the complementors. This is thus more the domain of Contract Law than the one of Competition Law.

\section{Conclusion}

Our research is about competition law in algorithm-based markets. Every market is becoming a digital market, hence its relevance. Now, its main contribution is about isolating information as the primary instrumental variable. This is why we build our formal theory around the information. As a result, another contribution is about the need to shift from a data-driven paradigm to a decisiondriven paradigm for firms (augmented intelligence).

Our research applies to algorithm-based markets for symmetric and asymmetric (keystone players) markets. It is essential for P2B, but readers should also consider the formal theory we propose in the P2C context. Another context to consider is the global context.

The formal framework we propose in this article puts forward - maybe in a bold way - the core instrumental variable we believe regulators should focus on information. It can be done in an ex-ante (de Marcellis-Warin et al., 2020c) or ex-post way. The information ownership and control through algorithms that gatekeepers enjoy over the overall market and the complementors is vital in the market dominance analysis. Competition law and contractual law analysts should focus on the information ownership and control as the E.U. Commission case initiated against Amazon in October 2020 and the U.S. one against Google initiated in December 2020 demonstrate. The model highlights the vacuum effect generated by a platform that integrates its complementors' information. The model clarifies that this vacuum effect (the multi-sided platform's inner dynamics) has replications on the overall market (the Competition Law domain). In this article, we wanted to model the platform

${ }^{14}$ FTC v. Gratz, 253 U.S. 421 (1920) 
dynamics - inside and outside - and better understand the implicit assumptions we find in new proposed regulations such as the DMA.

Further research is needed to craft legal tools to carefully assess and measure the degree of information ownership and control to have correct metrics and jurisprudence.

It is indeed essential to avoid some detrimental market dominance in terms of market surplus and innovation, but it is also equally essential to benefit from the incredible innovation that firms can now mobilize (de Marcellis-Warin et al., 2020b). In short, regulators need to be able to draw the line between gatekeepers and keystone players, as Nicolas Petit (2020) states through his proposal to differentiate competition law enforcement for already tipped and not yet tipped markets. We should also note that the DMA itself introduces such a distinction between actual and potential gatekeepers.

\section{References}

Bougette P., Budzinski O., and Marty F., (2019), "Exploitative Abuse and Abuse of Economic Dependence: What Can We Learn from an Industrial Organization Approach?", Revue d'Economie Politique, 129(2), pp. 261-286.

Bougette P. and Marty F., (2020), "Information Exchange among Firms: The Coherence of Justice Brandeis' Regulated Competition Approach," GREDEG Working Paper, 2020-56, December

Carlton D. W., and Perloff J. M., 2005. Modern Industrial Organization, $4^{\text {th }}$ edition, Pearson.

de Marcellis-Warin N. and Warin Th., 2020a. «Government 4.0 and Evidence-Based Policies: A.I. and Data Analytics to the Rescue». In Handbook of Artificial Intelligence and Robotic Process Automation: Policy and Government Applications, Anthem Press, 31.

de Marcellis-Warin, N., Munoz J. M., and Warin Th., 2020b. «A.I.in Business: Seeing through the Fog of War.» California Management Review. https://cmr.berkeley.edu/2020/02/ai-fog-of-war/.

De Marcellis-Warin, N., Thelisson E., Marty F., and Warin Th., 2020c. "Artificial Intelligence and Market Manipulations: Ex-ante Evaluation in the Regulator's Arsenal,» CIRANO Working Paper Series, 2020s-64, December. https://cirano.qc.ca/files/publications/2020s-64.pdf

Fisher-Ellison S., (2016), "Price search and obfuscation: an overview of the theory and empirics" in Handbook on the Economics of Retailing and Distribution, Basker E., ed, chapter 12, pp. 287-305, Edwar Elgar.

Gawer A. and Cusumano M.A., (2002), Platform Leadership: How Intel, Microsoft, and Cisco drive industry innovation, Boston, MA, Harvard University Press.

Geradin D. and Katsifis D., (2019), "Google's (Forgotten) Monopoly - Ad Technology Services on the Open Web," TILEC Discussion Paper, DP 2019-30, Tilburg University, May.

Geradin D. and Katsifis D., (2020), "Taking a dive into Google's Chrome cookie ban," Geradin Partners Thought Paper Series

Grandstrand 0. and Holgersson M., (2020), "Innovation Ecosystems: A Conceptual Review and New Definitions," Technovation, 90-91, https://doi.org/10.1016/j.technovation.2019.102098

Lande R.H., (1982), « Wealth Transfers as the Original and Primary Concern of Antitrust: The Efficiency Interpretation Challenged ,» Hastings Law Journal, volume 34, pp.65-151. 
Marty, Frédéric. 2017. « Algorithmes de prix, intelligence artificielle et équilibres collusifs. » Revue internationale de droit economique, t. XXXI(2): 83-116.

Marty F., and Warin Th., 2020a. « Concurrence et Innovation Dans Les Écosystèmes Numériques à l'ère de l'intelligence Artificielle. » Concurrences / Competition Law Review 2020-1: 36-41.

Marty F., and Warin Th., 2020b. "Innovation in Digital Ecosystems: Challenges and Questions for Competition Policy.” CIRANO Working Paper Series, 2020s-10.

https://cirano.qc.ca/files/publications/2020s-10.pdf

Marty F., and Warin Th., 2020c. "Keystone Players and Complementors: An Innovation Perspective." CIRANO Working Paper Series, 2020s-61. https://cirano.qc.ca/files/publications/2020s-61.pdf

Marty F., and Warin Th., 2020d. "The Use of A.I.by Online Intermediation Platforms.” Delphi Interdisciplinary Review of Emerging Technologies2(4): 217-25.

https://doi.org/10.21552/delphi/2019/4/11

Marty F. and Pillot J., (2019), "Cooperation, Dependence and Eviction - How Platform-To-Business Relationships in Mobile Telephony Ecosystems Should Be Addressed in A Competition Law Perspective?", CIRANO Working Paper Series, 2019s-01, January.

Petit N., (2020), Big Tech \& the Digital Economy - The Molygopoly Scenario, Oxford University Press.

Srinivasan D., (2020), "Why Google Dominates Advertising Markets: Competition Policy Should Lean on the Principles of Financial Market Regulation," Stanford Technology Law Review, 24(1), pp.55-125175.

Warin, Thierry, and Daniel Leiter. 2012. «Homogenous goods markets: an empirical study of price dispersion on the internet.» International Journal of Economics and Business Research, 4(5):

514-29. https://dx.doi.org/10.1504/IJEBR.2012.048776

Warin, Thierry, and Antoine Troadec. 2016. "Price Strategies in a Big Data World." Encyclopedia of E-Commerce Development, Implementation, and Management: 625-38, March. 